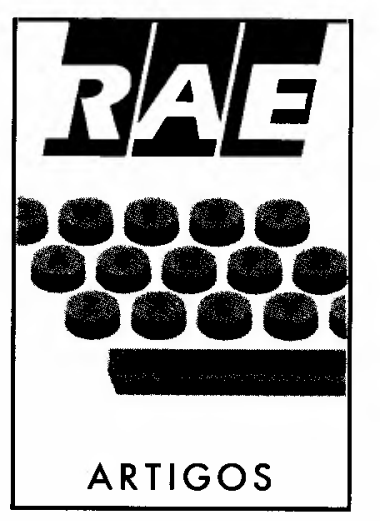

\title{
O PROCESSO SUCESSÓRIOE A ABERTURA DE CAPITAL NAS EMPRESAS BRASILEIRAS: OBJETIVOS CONFLITANTES
}

A abertura de capital de uma companhia pode não ser a solução adequada a problemas de sucessão em empresas familiares brasileiras.

To "go public" may not be an inadequate solution for the succession problems in Brazilian family companies.

\section{PALAVRAS-CHAVE:}

Sucessão, abertura de capital, mercado de capitais brasileiro.

KEY WORDS:

Sucession, going public, Brazilian capital market.

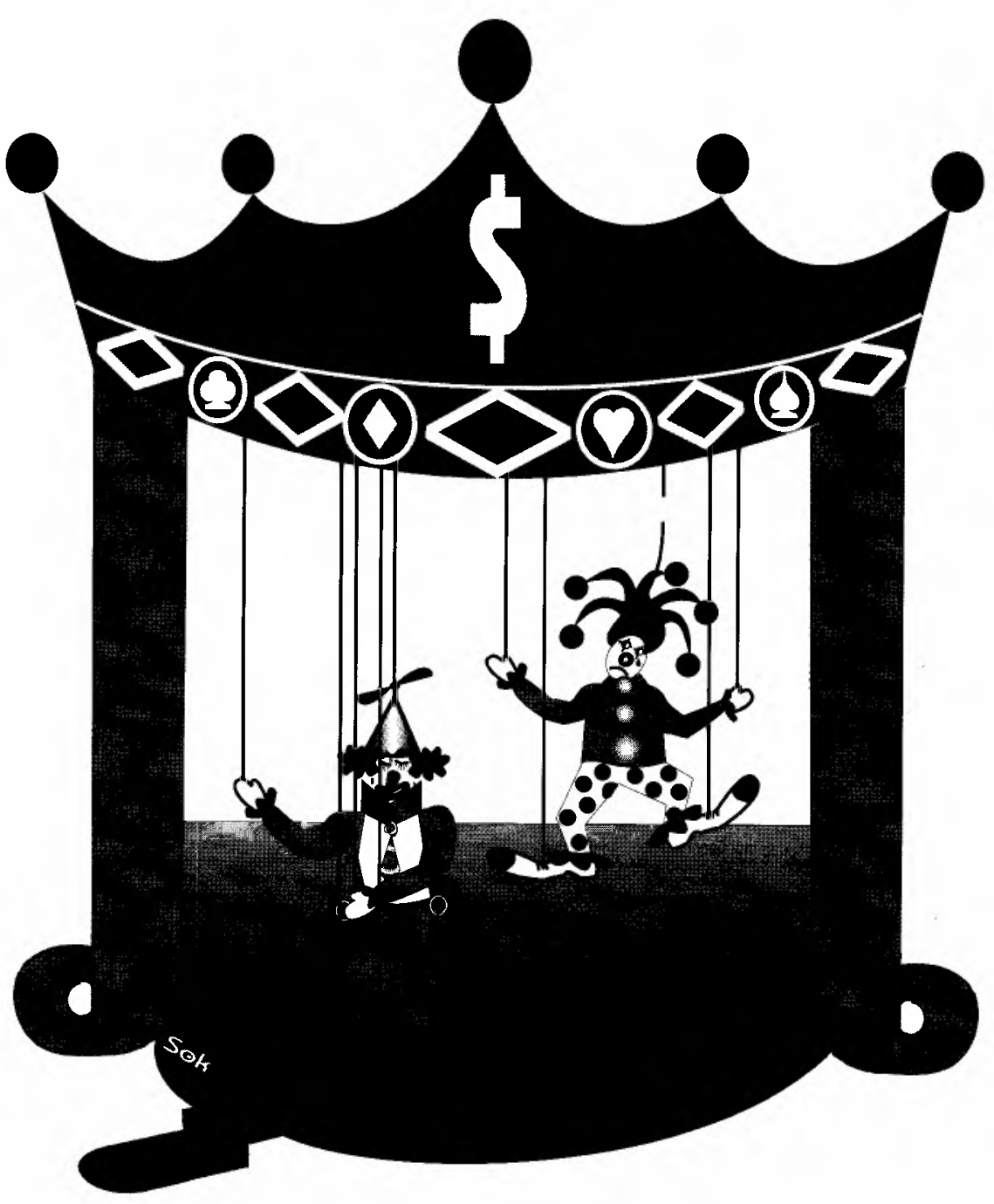


Nos últimos tempos, muito se tem discutido sobre a sucessão nas empresas. Várias soluções têm sido apresentadas para resolver a "passagem da tocha" do sucedido para o sucessor, tais como profissionalizar a empresa familiar ou preparar e, posteriormente, escolher os sucessores originários da própria família para essas companhias. No entanto, pouco se discute sobre a forma de enfrentar os distintos anseios de todos os herdeiros, seja a solução adequada para problemas de sucessão, pois verifica-se a existência de uma grande diferença entre os valores das ações desejados por seus proprietários e os pagos no mercado de capitais brasileiro.

Ao longo deste trabalho, procuraremos mostrar quais são as características das sociedades anônimas, no que se refere à legislação societária; as peculiaridades do mercado de capitais brasileiro; o conceito e o funcionamento da abertura de capital de uma empresa; o histórico de crescimento das empresas e os fatores que têm levado seus controladores à busca de uma solução para suas sucessôes; as possibilidades de atuação dos diversos agentes na sucessão e, finalmente, a questão da abertura de capital como uma

que também é parte da administração do processo sucessório, garantindo a liquidez destes como acionistas ou a eventual saída dos insatisfeitos com a direção tomada no processo.

Uma das soluções apresentadas para o problema da sucessão - comumente ouvida e explicitada por Casagrande Neto - é garantir a liquidez das ações, no mercado de capitais, através da abertura de capital das empresas. Para que essa solução seja eficiente, é necessário que as características societárias das empresas e do mercado, cujas açōes serão negociadas, sejam compatíveis entre si e com a idéia básica de que as ações ordinárias tenham liquidez a um preço adequado.

Duas características são muito importantes nas empresas brasileiras: a existência de um grupo controlador bem definido, representado por $50 \%$ mais uma das ações com direito a voto; o valor existente no fato de o controle de uma empresa ser exercido sem que seja necessário possuir metade do valor total investido.

Essas características, adicionadas às peculiaridades do mercado de capitais brasileiro, podem levar à idéia de que a abertura de capital de uma companhia não possível solução para o processo sucessório nas empresas brasileiras e para seus empresários.

\section{CARACTERÍSTICAS DAS SOCIEDADES ANÔNIMAS NO BRASIL}

A definição das características societárias das empresas brasileiras é fundamentada na Lei n 6.404, datada de dezembro de 1976, e na legislação complementar, composta pelas instruções e regulamentações editadas pela Comissão de Valores Mobiliários - CVM, órgão regulador e fiscalizador do mercado de capitais.

No que se refere à tipificação das ações, três espécies: as ordinárias, as preferenciais ou as de fruição. A diferença entre elas está na natureza dos seus direitos ou das vantagens conferidas aos titulares das ações.

As ordinárias são ações que têm direitn a voto, podendo, portanto, influir nas decisōes e nos rumos da empresa. As preferenciais são aquelas que têm prioridade no recebimento dos dividendos e, em caso de liquidação da empresa, no reembolso no capítulo III da referida lei, encontramos
1. CAsagrande neto, $H$. Abertura do capital de empresas no Brasil: um enfoque prático. 2. ed. Sāo Paulo: Atlas, 1989. 
do capital. As de fruição são as que continuam a receber parcelas do lucro na forma de dividendos, após o reembolso do equivalente à sua parte do capital social da empresa.

$\mathrm{Na}$ realidade, verificamos que as diferenças de direitos pecuniários entre as ordinárias e as preferenciais diferem do que é explicitado na lei. Os dividendos, que deveriam ser um direito prioritário das preferenciais, são considerados em iguais condições àqueles pagos às ordinárias. Conforme possibilidade constante no artigo $202, \S 1^{\circ}$ e $\S 2^{\circ}$, da Lei $n^{\circ} 6.404$ / 76 , verifica-se que a grande maioria das companhias abertas exerce, no bojo do seu estatuto social, a prerrogativa do pagamento de dividendos como uma cláusula de dividendo mínimo de $25 \%$ sobre o lucro líquido ajustado, a ser pago em igualdade de valores e de tempo para ambas as classes de ações. A conseqüência de tais procedimentos resulta na inexistência da preferência "de fato" pelos dividendos para a classe de ações preferenciais.

O mesmo não acontece no caso da liquidação da empresa, onde o direito prioritário das preferenciais é mantido, ou seja, a devolução do capital social deve ocorrer primeiramente para as ações preferenciais e, depois, para as ordinárias.

A quantidade de ações ordinárias e preferenciais a serem emitidas, e a relação entre elas, encontram-se reguladas em lei. Através do artigo $15, \S 22^{\circ}$, da Lei $\mathrm{n}^{\circ}$ 6.404/ 76 , é possível emitir ações preferenciais sem direito a voto, ou sujeitas à restrição do exercício de voto, desde que não ultrapasse $2 / 3$ do capital total, sendo permitida a existência de empresas com $100 \%$ do seu capital social composto de ordinárias, mas não com $100 \%$ de preferenciais. O limite máximo para estas últimas é $2 / 3$ do capital total.

O controle acionário de uma sociedade anônima é dado por $50 \%$ mais uma das ações ordinárias. O controlador, ou grupo controlador, será aquele que possuir esse bloco de ações e, conseqüentemente, terá a possibilidade de governar e comandar a companhia ao eleger os membros do conselho de administração e, em decorrência, nomear a diretoria para a realização da gestão.

Ao examinarmos a possibilidade do ca- pital social de uma sociedade anônima ser constituído de $1 / 3$ de ações ordinárias e $2 / 3$ de ações preferenciais e a existência de um controlador bem definido, com $50 \%$ mais uma das ações com direito a voto, poderíamos afirmar que este pode realizar uma alavancagem cinco vezes maior que o seu capital investido. Assim, numa empresa cujo valor de capital é $\$ 100$, são necessários $\$ 16,7$, na forma de ações ordinárias, para que sejam mantidos o comando e o controle.

Se aliarmos essas três características, dividendos indistintos entre as diversas classes de ações, a existência de um grupo controlador e a possibilidade de emissão de $1 / 3$ de ordinárias e $2 / 3$ de preferenciais, podemos verificar que é bastante fácil para um grupo controlador manter o controle da empresa durante muito tempo, bastando para isso deter, aproximadamente, $16,7 \%$ do capital total da empresa em ações ordinárias. Em cada nova chamada de capital, esse grupo controlador necessitará somente de $1 / 6$ do montante total da nova subscrição para manter sua posição acionária.

A existência de um grupo controlador bem definido é uma característica do mercado brasileiro, bastante distinta da de outros mercados. Esse grupo controlador pode ser composto por um número qualquer de pessoas ou somente por uma, denominada controlador. Na grande maioria das empresas negociadas em bolsas de valores norte-americanas, verificamos a existência de um grande número de acionistas que não possuem mais do que 5 ou $6 \%$ do capital total, não se caracterizando, assim, uma posição de controle.

No mercado brasileiro, ao observarmos as 650 empresas abertas negociadas em bolsa de valores, notamos que são poucas as que não têm o controle bem definido por um grupo controlador. Podemos citar o caso da Brasmótor, na qual o controle está dividido entre dois grupos (Whirlpool e Bradesco), o caso da Drogasil, que possui um número bastante grande de acionistas ordinários, e o caso da Alpargatas, cujo controle está divido em três grupos (Brasmotor, Camargo Corrêa e Bradesco).

A existência de um grupo controlador nas companhias brasileiras de capital aberto faz com que a relação entre controle e gestão na organização empresarial - 
entendendo-se por controle as açōes ordinárias com direito a voto, oriundas do capital aportado pelos sócios, e por gestão o trabalho contributivo dos aḍministradores - seja bastante distinta da relação existente na grande maioria das empresas. Podemos afirmar que, no Brasil, a última definição sempre cabe ao controlador, ou ao representante do grupo controlador. $O$ que nāo acontece em outros países, onde a eleição dos membros do conselho de administração é feita por milhares de acionistas reunidos em assembléia geral.

DeAngelo e DeAngelo ${ }^{2}$ argumentam que a acumulação de votos e o conseqüente controle da empresa beneficiam seu detentor tanto mais quanto mais forem os membros da família controladora que estiverem envolvidos na gestão da empresa.

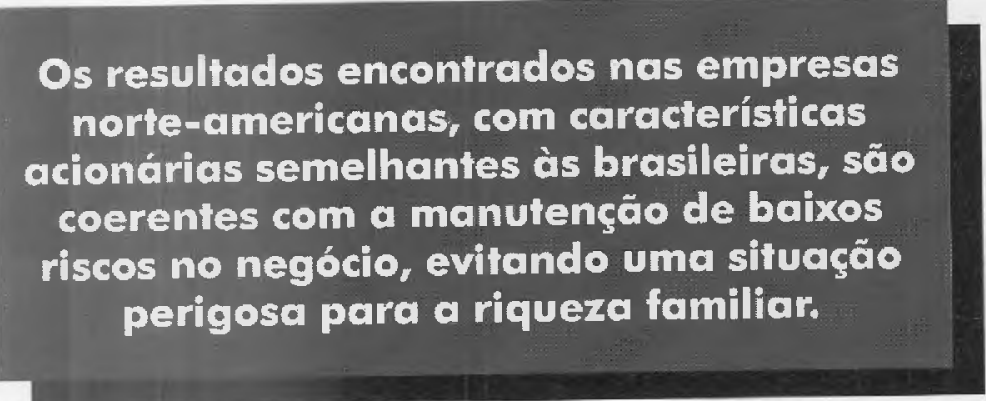

82 empresas listadas nas bolsas norteamericanas, com baixíssimos níveis de endividamento, concluíram que: os gestores dessas empresas possuem parcelas de ações significativamente superiores às das empresas mais endividadas; existe um maior envolvimento familiar nessas empresas quando comparadas às empresas mais endividadas; quanto maior for a participação acionária da família, maior será sua participação na gestão; a liquidez nas empresas estudadas é muito maior que nas correspondentes do mesmo setor que são mais alavancadas.

Como podemos observar, os resultados encontrados nas empresas norte-americanas, com características acionárias semelhantes às brasileiras, são coerentes com a manutençāo de baixos riscos no negócio, evitando uma situação perigosa para a riqueza familiar.

A manutenção de baixos riscos operacionais acrescidos de pouco endividamento, objetivando a segurança do patrimônio da família, são indicativos de uma pequena velocidade de crescimento nos

Conforme Jensen e Meckling, ${ }^{3}$ ao evitar o endividamento, a gestão de uma empresa objetiva reduzir a possibilidade de falência $e$, conseqüentemente, a transferência de riqueza dos acionistas para os credores. Isso acontece, especialmente, quando os membros da família, além de controladores e possuidores de parte relevante de seus ativos na empresa, também forem gestores da mesma.

O controlador, por possuir a maioria de seus ativos investidos nessa empresa, e com a conseqüente não diversificação de seus investimentos, busca como alternativa uma redução de seu risco individual fazendo com que a empresa tenha um. risco reduzido. Ele comandará uma estrutura de capital - relação entre endividamento e capital - pouco alavancada, com baixos níveis de dívidas para uma grande quantidade de recursos não onerosos como solução para evitar um alto risco no negócio e para si próprio.

Agrawal e Nagarajan ${ }^{4}$ ao pesquisarem negócios. Forma-se um círculo vicioso de baixos riscos e baixas taxas de crescimento.

Essas características serão extremamente importantes para delinear o perfil sucessório e o funcionamento das empresas familiares brasileiras.

\section{CARACTERÍSTICAS DO MERCADO DE CAPITAIS BRASILEIRO}

Dentre as diversas características peculiares do mercado de capitais brasileiro, três têm especial interesse para nosso estudo: os valores atribuídos para as açōes pelos diversos agentes participantes desse mercado, a liquidez nas bolsas, de um modo geral, e das ações ordinárias e preferenciais, em especial, e a percepção do risco existente no investimento em ações.

Os valores existentes, ou que podem ser considerados pelos diversos agentes,

\section{Valores das ações}

2. DeANGELO, H., DeANGELO, L. Managerial ownership of voting rights: a study of publlo corporations with dual classes of common shares. Journal of Financial Economics, v. 14, p $33-69,1985$

3. JENSEN, M. C, MECKLING, W $H$. Theory of the firm: management behavior, agency costs and ownership structure. Journal of Financial Economics, v. 3, p. 305-60, 1976.

4. AGRAWAL, A., NAGARAJAN, N. J. Corporate capital structure, agency costs and ownership control: the case of all-equity firms. Journal of Finance, $v, X L V$, ก. 4, p. 1325-31, Sep. 1990. 
recebem diversos nomes e diversas características.

O primeiro deles é o valor nominal, que é o montante expresso pelo capital social da empresa dividido pelo número de ações existentes. Algumas empresas possuem explicitamente esse valor, outras apresentam apenas o valor nominal teórico, já que as ações em si não possuem estatutariamente um valor nominal.

O segundo é o valor patrimonial, que pode ser subdividido em contábil e real. O valor patrimonial contábil é o patrimônio líquido contábil da companhia dividido pelo número de ações existentes.

Devido ao processo inflacionário incorrido durante os últimos anos no Brasil, podemos encontrar esse valor patrimonial contábil bastante defasado, pois ele não apresenta a escrituração do valor real dos ativos da companhia. Isso ocorrerá sempre que a correção monetária aplicada aos ativos no balanço não espelhar a valorização de mercado dos bens, e também quando a empresa não tiver realizado a reavaliação desses bens. Portanto, podemos obter um segundo valor patrimonial ao considerarmos o valor patrimonial real, ou seja, o valor patrimonial da companhia acrescido de toda a reavaliação dos bens a ela pertencentes.

Ainda cabe lembrar que esse valor patrimonial real não considera todos os intangíveis existentes na companhia, tais como marca, valor e o going concern (andamento dos negócios), entre outros.

$O$ terceiro valor é o de mercado, resultante do encontro das curvas de oferta $e$ de procura por ações nas bolsas de valores. Esse valor será conseqüência direta das características peculiares de nossas bolsas, como, por exemplo: baixa liquidez, compradores institucionais responsáveis pela grande maioria dos negócios e concentração de negócios em poucas empresas.

A perspectiva de resultados da empresa nos dará o quarto valor. Ela pode ser traduzida pelo valor presente do fluxo futuro dos dividendos da companhia em análise, considerando-se uma taxa de juros composta pela taxa livre de risco e por um fator característico do risco da empresa em questão. Esse valor é considerado o real valor das ações em mercados desenvolvidos, nos quais haverá uma semelhança entre o valor decorrente da perspectiva de resul- tados e o valor de mercado de uma ação.

Ao analisarmos qual seria o correto valor para as ações no mercado brasileiro, deparamos com uma realidade bastante diversa daquela encontrada nos mercados desenvolvidos. Aqui, o valor de mercado, embora tecnicamente o mais correto, é menor que o valor patrimonial das companhias e menor ainda que o seu valor patrimonial real.

Na média, o valor de mercado é cotado, historicamente, entre 25 a $35 \%$ do valor patrimonial das companhias, o que é reduzido para cerca de $15 \%$, caso tomarmos como referência o valor patrimonial real dessas empresas. Lembra-se que, no mercado norte-americano, o valor de mercado é bastante superior ao valor patrimonial contábil das companhias.

\section{Liquidez}

Muito embora não seja o nosso objetivo estudar a liquidez das ações das empresas nos mercados de bolsas de valores brasileiras, dois fatores assumem especial relevância em nosso estudo: o comportamento da carteira teórica representativa do mercado (índice Bovespa - Bolsa de Valores de São Paulo) e a liquidez relativa entre as ações ordinárias e preferenciais de uma mesma sociedade anônima.

A relevância desses aspectos fica mais evidente ao examinarmos a composição dos índices Bovespa, conforme a tabela 1.

A partir desses dados, verificamos que o número de ações participantes desse índice cresceu de 1977 até 1987, caindo severamente após esse período de grande atividade nas bolsas.

O número de empresas estatais não sofreu grandes alterações. A quantidade de instituições financeiras reduziu-se somente em 1992, muito provavelmente pelo fato de o ano anterior ter sido fraco em termos de resultados para os bancos. $\mathrm{E}$ as empresas multinacionais, realizando um caminho semelhante à composição do índice como um todo, cresceram até 1987 e, depois, decresceram.

O número de empresas cujas ações ordinárias são negociadas na Bolsa de Valores de São Paulo reduziu-se de 30 ( $51,72 \%$ do número total de empresas) em 1977 para $8(16,67 \%$ do número total de empresas) em 1992/93, representando $3,29 \%$ do valor total da carteira. Verifica- 


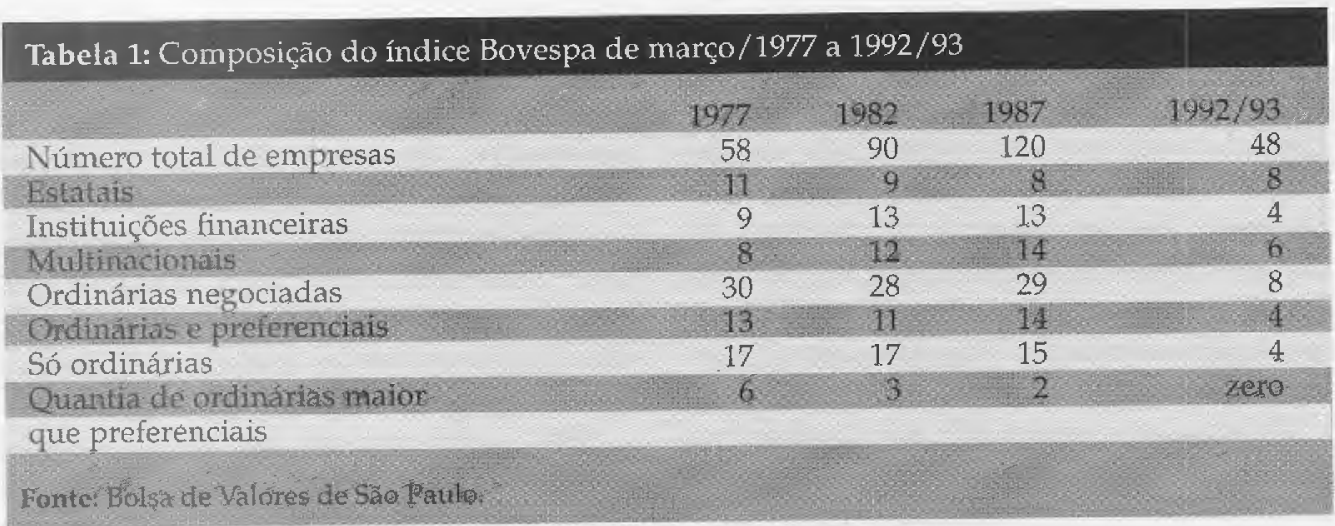

se que, mesmo com o aumento do número de empresas no indice em 1987, o número de ações ordinárias permaneceu muito reduzido, compondo o capital de 29 das 120 empresas, representando $24,2 \%$ do total.

A quantidade de empresas que comparecia nos pregões com ações ordinárias e preferenciais, assim como aquelas que só compareciam com ordinárias, foi reduzida de 13, em 1977, para 4, em 1992/93. Como conseqüência, observa-se a queda do número de empresas que eram negociadas unicamente com ordinárias de 17, em 1972, para 4, em 1992/93. A redução desse último grupo pode ser atribuída às empresas multinacionais que fecharam capital (Anderson Clayton), àquelas que resolveram emitir preferenciais (Belgo Mineira e Klabin), ou ainda, às empresas nacionalizadas (Alpargatas).

Mas o dado que mais impressiona é o resultante da comparação entre as empresas que apresentavam maior liquidez para suas ações ordinárias que para as preferenciais. Eram seis, em 1977, e nenhuma, em 1992/93.

Esses dados são de especial interesse para o estudo da sucessão nas empresas, tendo em vista que os controladores, ou seus sucessores, possuem ações ordinárias e não preferenciais e terăo que se desfazer das mesmas para obter a liquidez desejada.

\section{Riscos}

Os riscos associados aos investimentos em bolsa de valores, sejam políticos, econômicos ou sociais, são muito importantes para o desenvolvimento do mercado de ações.

O investidor usa sua percepção de risco para descontar ao valor presente o fluxo futuro de dividendos de uma ação. Essa atitude deve ser utilizada como fator que amplie a garantia do investidor sobre o futuro da empresa em que está investindo. Quanto maior o risco envolvido, maior será a taxa de desconto. Conseqüentemente, menor será o valor presente do fluxo futuro de dividendos e, portanto, o valor da ação.

Ao analisar a situação brasileira, verificamos que os riscos percebidos servirão para reduzir muito os fluxos futuros, encontrando um valor presente bastante inferior ao esperado. Como conseqüência natural, teremos valores baixos para as ações, representados pelas cotações desses ativos no mercado bursátil.

No mercado norte-americano, encontra-se uma maior estabilidade econômica, o que faz com que - valor de mercado das empresas seja muito maior que o seu valor patrimonial contábil, ou mesmo, em alguns casos, maior que seu valor patrimonial real. 


\section{ABERTURA DE CAPITAL}

A partir do momento em que uma sociedade anônima vai ao mercado de capitais com a possibilidade de levantar recursos, fica estabelecida a "abertura de capital". Essa é uma definição prática, pois isso é o que na realidade acontece ao se estabelecer a relação entre empresa e mercado de capitais.

Existem duas modalidades de abertura de capital, ou seja, duas formas pelas quais a CVM autoriza o registro de companhia aberta: fazendo uma emissão de ações ou. de debêntures, simples ou conversíveis e provando a existência de um número bastante grande de acionistas na empresa.

$O$ processo de abertura é bastante simples. Ele se instala a partir do desejo dos atuais acionistas da companhia a ser expresso pela adequada deliberação na Assembléia Geral Extraordinária - AGE - a ser realizada com esse objetivo. $O$ passo seguinte é estabelecer a possibilidade do exercício do direito de preferência na subscrição dos valores mobiliários emitidos pelos acionistas existentes. E, a seguir, deflagrar a colocação pública, junto aos investidores em geral, por um grupo de instituições financeiras contratado para esse fim.

O objetivo básico da abertura de capital é a obtenção de recursos, que poderão ocorrer na forma de capital, via ações, ou na forma de dívidas, via debêntures.

Além desse objetivo, a abertura de capital pode ser caracterizada como a possibilidade dos controladores encontrarem liquidez para seus investimentos anteriormente realizados na fundação e no crescimento da companhia.

No nosso caso específico, que é o exame da sucessão das empresas e seu relacionamento com o mercado de capitais, através da abertura de capital de uma empresa, novos investidores interessados em comprar parcelas do capital dessa companhia seriam a fonte da liquidez para os sócios. Estes se desfariam de parte de seus investimentos anteriores, vendendo ações de sua propriedade, em bolsa, para novos investidores. $\mathrm{E}$, assim, seria garantida a liberdade para a realização do investimento feito por parte dos empresários fundadores.

O preço de emissão das ações deve ser regido pelos parâmetros citados no artigo $170, \S 1^{\circ}$, da Lei $n^{\circ} 6404 / 76$, sendo três as possibilidades: o preço de mercado, a perspectiva de resultados e o valor patrimonial da companhia. Em nenhuma dessas possibilidades, o preço de emissão pode ser inferior ao valor nominal das ações ou permitir a diluição injustificada dos antigos acionistas, mesmo quando lhes é garantido o direito de preferência.

Com a abertura de capital ou da primeira busca de recursos no mercado de capitais via emissão de ações, o preço de mercado das ações como parâmetro alternativo torna-se completamente inócuo e inadequado, simplesmente, por não existir. Como indicativo, poderíamos fazer uma comparação entre os valores das ações das empresas do mesmo setor econômico (as concorrentes) que estivessem sendo negociadas em bolsa de valores. Cabe lembrar que cada empresa possui as características operacionais e financeiras próprias, o que torna esse processo comparativo apenas um balizamento da reação dos investidores ao setor e às empresas abertas desse setor.

Mesmo tendo como base as outras duas possibilidades expressas em lei para balizamento do valor de emissão, devemos lembrar que, no momento de abertura do capital, a empresa é menos conhecida por parte dos seus futuros eventuais investidores e esse menor conhecimento gera maior percepção de risco. Como conseqüência, ocorre uma redução dos preços a serem pagos pelas ações que estão sendo emitidas. Assim, todo o risco adicional da abertura é compensado com um preço menor a ser pago.

As operações de underwriting, no Brasil, podem ser feitas com garantia firme ou melhores esforços. Garantia firme é a garantia de subscrição pelos banqueiros garantidores da operação, que ficam com as ações caso elas não sejam colocadas junto aos investidores finais.

A operação de underwriting, com melhores esforços, acontece quando os banqueiros realizam os seus melhores esforços para coloçar as novas ações e não conseguem, o que leva a empresa a tentar encontrar, através de seu esforço próprio, alguém para subscrevê-las.

O costume brasileiro é de que as operações sejam feitas com garantia firme 
sendo que aquelas com melhores esforços praticamente inexistem.

Os banqueiros cobram uma comissão de garantia firme que varia entre 5 e $10 \%$ do valor total da emissão. Podemos verificar que essa comissão é muito baixa quando comparada com as altas variações encontradas nos pregōes das bolsas de valores pregão). Então, concluímos que essa coincorrido pelos banqueiros de uma eventual desvalorização das ações no mercado. zidos a melhorar a qualidade de seus riscos, dando preços às ações a valores inferiores àqueles que seriam os "preços justos".

Como podemos observar, todo o mecanismo de funcionamento no mercado de (às vezes, chegam até a $10 \%$ em um único missão cobre apenas parcialmente o risco Como solução, esses banqueiros são indu-

um grande empreendimento, mesmo quando comparado também aos seus concorrentes (no mercado).

Esse desenvolvimento também é identificado no plano familiar do empreendedor. $O$ controlador tem os seus filhos. Em algum momento do futuro, o controlador faz com que seus herdeiros assumam suas posiçôes no negócio. Estes últimos, por sua vez, vão ter outros filhos, que também vão assumir seus cargos no negócio. Em função do número crescente de dependentes, controlador, filhos e netos, cabe à empresa manter seu papel de fonte geradora dos recursos econômicos para essa família.

Os negócios brasileiros são fundamentalmente caracterizados pela participação da família, que exerce posições de comando na empresa. $O$ bom relacionamento entre os seus membros está diretamente vinculado ao andamento do negócio, no momento presente e na decisão sobre o futuro do empreendimento.

Quanto à continuidade do negócio e ao relacio-

açũes brasileiro faz com que a emissão de ações seja realizada a preços bastante baixos. Existe uma tendência constante de baixar os preços das ações a serem lançadas, como forma de garantir os riscos incorridos. Isso fica mais evidente ainda quando consideramos o momento da abertura de capital em si, onde o desconhecimento sobre a empresa e sua gestão é maior, ocasionando uma relação entre o valor de emissão e o valor patrimonial mais reduzido que as emissões de empresas anteriormente abertas.

\section{HISTÓRICO DOS CONTROLADORES}

Na busca de soluções para a sucessão nas empresas, é muito importante o estudo da formação dos grupos controladores e da evolução de seus negúcius.

No espírito brasileiro, uma empresa resulta do desejo de um empreendedor com visão futurística de montar seu próprio negócio. $O$ dono passa a desenvolvê10, transformando seu negócio inicial em namento familiar, dois elementos são muito importantes: a possibilidade de disputa entre os familiares para a definição do sucessor e a necessidade da manutenção do nível econômico-financeiro de todos os herdeiros.

Com o passar dos anos, aumenta o número de pessoas envolvidas nas decisões relevantes da empresa. No início, somente o fundador decidia, depois, seus filhos e - netos passam a ter que negociar entre si para encontrar a decisão comum para o andamento dos negócios. O número de participantes em cada decisão passa a ser muito grande, aumentando a possibilidade dos confrontos e formaçāo de grupos internos no poder.

A busca de estabilidade financeira para as famílias, por parte de todos os herdeiros, passa a ser uma decisão relevante nas posições a serem exercidas por essas pessoas. Elas têm dois caminhos a seguir: encontrar uma colocação profissional dentro da empresa ou uma atividade extra-empresa. O gosto pelo negócio e a capacitação 
individual serão pontos-chave na definição de qual caminho deve ser seguido.

Os mais capazes terão condições de obter colocação na empresa ou no mercado de trabalho, ao passo que os menos capazes terão dificuldades para encontrar seu espaço e, portanto, tentarão "encostar$\mathrm{se}^{\prime \prime}$ na companhia como se essa fosse a completa solução para seus problemas profissionais e financeiros.

Quando examinamos o crescimento das empresas, verificamos que este não ocorre na mesma proporção que o das famílias. No momento em que existe um descompasso entre o crescimento das empresas $\mathrm{e}$ o das famílias, quando as últimas crescem em ritmo maior, constatamos que o "nível de vida" dos proprietários pode baixar, à medida que as receitas oriundas do negócio não comportam a manutenção dos herdeiros no mesmo patamar atingido anteriormente. Pode-se afirmar que isso resulta em um problema grave de necessidade de "reforma agrária" nas empresas, ou seja, a família cresceu mais que o tamanho da empresa. $\mathrm{O}$ número de beneficiários é muito maior que o sustentável pela empresa, originando a necessidade de migração de alguns para outras atividades.

Todos esses elementos promovem uma relação muito delicada entre os herdeiros da empresa, o que, independente da competência destes, pode gerar um processo muito explosivo.

\section{SUCESSÃO NAS EMPRESAS}

No que tange aos possíveis relacionamentos com a empresa, os herdeiros podem assumir três posições: ficar na empresa e ocupar um cargo administrativogerencial; permanecer como acionista e não desempenhar qualquer função dentro da empresa ou sair da empresa vendendo sua posição acionária no capital da mesma.

Na primeira posição, onde existe a manutenção do herdeiro na empresa em um cargo gerencial, seu patrimônio estará sendo cuidado por ele mesmo e os recursos para a sua manutenção mensal estarão garantidos. Para ele, não terá importância a liquidez eventual de suas ações. Ele está garantido com o poder, na gestão do diaa-dia, e com a receita mensal oriunda do fruto do seu trabalho.

Aquele herdeiro que mantiver a sua participação acionária sem trabalhar na empresa vai querer um incremento passo a passo na sua posição patrimonial, com o crescimento da empresa, mas terá dúvidas sobre os riscos incorridos e desejará obter uma receita advinda desse patrimônio. Para esse herdeiro, de nada lhe adianta-rá ficar com o patrimônio, sem que isso lhe gere recursos para assegurar o investimento e complementar a manutenção do seu nível de vida. Nesse caso, os dividendos a serem distribuídos pela empresa, na forma de dinheiro e na quantidade que for proporcional à sua participação no capital social, serão muito relevantes.

Por outro lado, aquele que resolver sair da empresa, conhecido como o dissidente, vai querer, obviamente, a liquidez financeira para sua posição. Esses recursos serão a fonte para a realização de novos investimentos e para encontrar seu rumo profissional. Caso não consiga, ele vai tentar buscar uma das duas posições anteriores para, no mínimo, manter o nível de vida.

Vemos, portanto, a existência de dois elementos em comum nessas três posições possíveis de serem exercidas pelos herdeiros: manutenção mensal e liquidez para as posições patrimoniais. A necessidade de recursos para a manutenção mensal deve ser traduzida pelo salário ou pelos 


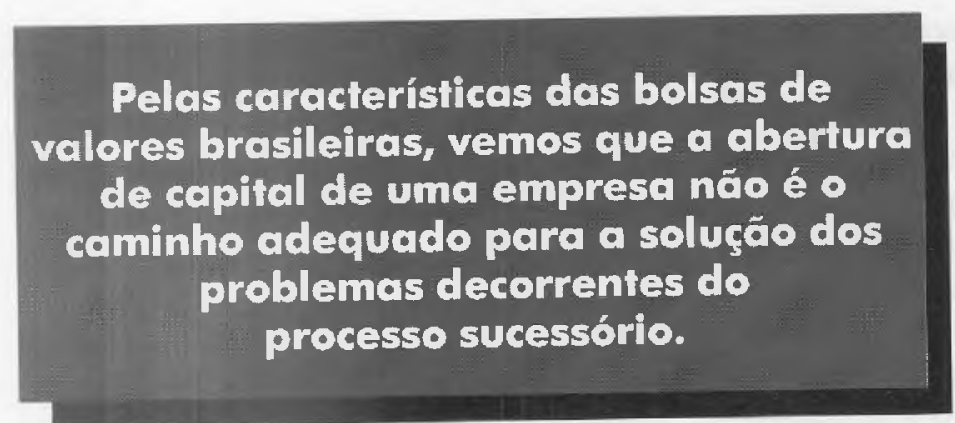

dividendos. Aliquidez, presente ou futura, para as posições patrimoniais individuais, pode ser obtida na venda dos bens, das açōes através de bolsa de valores ou buscando formas alternativas.

Caso a companhia seja uma companhia fechada, a venda em bolsa de valores será possível somente após a abertura de capital. A venda de ações em bolsa de valores deve considerar o valor passível de ser obtido. O valor para o controlador desses ativos não é o mesmo que para um investidor. As ações votantes e controladoras possuem um valor superior às demais de uma mesma empresa. ${ }^{5}$

O controlador, ou seus herdeiros, além da sua posição acionária, possui o poder de controle sobre toda a companhia. Conforme a teoria da agência, ${ }^{6}$ ele terá ganhos ao manter essa posição. Faz-se necessário lembrar também que, como a companhia está alavancada em. $1 / 3$ de ações ordinárias e $2 / 3$ de preferenciais, o controle será dado por $16,67 \%$ do capital total, fazendo com que a posição do controlador seja mais valorizada pela necessidade menor de recursos para sua manutenção. Então, o valor para o controlador fica cada vez mais distante do valor do mercado.

Se a venda em bolsa de valores for inadequada em função das diferentes expectativas do preço a ser obtido, devese buscar outras soluções. É possível, por exemplo, que os herdeiros que permanecerem na empresa comprem a posição do retirante, ou que se encontre um terceiro, extemo, para realizar essa operação. A possibilidade de troca dos ativos por dinheiro será encontrada com alguma facilidade, mas devemos atentar que o preço desses ativos pode ser bastante reduzido para obtermos uma proposta de compra.
Conforme estudos de Amihud e Mendelson,? a liquidez de um ativo é diretamente proporcional ao seu preço. Um ativo de baixa liquidez terá que reduzir seu preço para encontrar um comprador.

Algumas empresas apresentam a solução para o grande número de herdeiros através da montagem de uma holding de controle. Isso pode ser muito bom para aqueles que permanecerem nos cargos administrativos, assegurando o controle acionário da empresa e a continuidade da gestão, mas não será apreciado por aquele que, eventualmente, for o retirante, no presente ou no futuro. Isso se deve ao fato de que, quanto mais distante for a posição acionária detida pelo sócio que busca a sua retirada em relação à companhia operacional, mais difícil será para ele obter liquidez para seu investimento

As diferentes situações irão determinar os possiveis acordos entre os acionistas, que inviabilizarão a realização dos desejos dos eventuais dissidentes. Estes só perderão. Os acordos entre acionistas bloqueiam as posições acionárias de seus signatários e trazem a consequiente perda da liquidez. $O$ dissidente não encontrará comprador para sua posição acionária, pois dificilmente encontrará investidor para comprar sua posição sabendo do acordo entre os demais sócios. Por outro lado, dificilmente todos os signatários serão beneficiados igualmente. Os menos beneficiados sofrerão os prejuízos sem poderem retirar-se do acordo.

Tanto a existência de uma empresa holding de controle, quanto a realização de um acordo de acionistas tendem a aumentar e acirrar as dificuldades de relacionamento entre todos os sócios nos momentos de discórdia, em vez de facilitar a solução dos problemas.

\section{CONCLUSÃO}

Podemos verificar que é extremamente importante para a solução no processo sucessório a garantia de recursos para os
5. LEVY, H. Economic evaluation of voting power of common stock. Journal of Finance, v. 38 , ก. 1, p. 79-93, Mar. 1982.

6. JENSEN, M. C., MECKLING, W. H. Op. cit.

7. AMIHUD, $Y$, MENDELSON, $H$. Liquidity, asset prices and financial policy. Financial Analysts Journal, p. 56-66, NovDec. 1991. 
sucessores, via receitas mensais (salário), dividendos ou através da possível venda parcial de suas ações.

No caso de venda parcial das ações para complemento das necessidades financeiras do seu detentor ou venda total no caso de dissidência, o valor a ser obtido pelas ações passa a ter muita relevância e deve ser examinado com cuidado. Um valor muito pequeno não será suficientemente atrativo para o vendedor realizar a operaçäo.

Pelas características das bolsas de valores brasileiras, vemos que a abertura de capital de uma empresa não é o caminho adequado para a solução dos problemas decorrentes do processo sucessório. A liquidez é muito estreita para as açōes ordinárias, a negociação de títulos é muito concentrada e o preço pago pelas ações tem sido sempre muito inferior ao valor patrimonial real da companhia.

Os herdeiros, que originalmente detinham ações ordinárias, permutam-nas por preferenciais, objetivando maior liquidez, já que as segundas são mais líquidas que as primeiras. Entretanto, cabe lembrar que, uma vez feita a permuta, o retorno à situação anterior nãก é permitido. O poder de votar desaparece sem garantir a liquidez almejada.

Quando tratamos do valor a ser obtido pelo controle acionário de uma empresa, ou de uma parcela deste, que é um fator que aumentaria o valor das ações, fica muito maior a distância entre o preço de mercado e os anseios dos vendedores. Nesse caso, denota-se que o mercado acionário não corresponde às expectativas em termos de valor das ações desejado pelos controladores.

As características societárias das empresas, as do mercado bursátil e a posição da maioria dos investidores do mercado de capitais brasileiro permitem afirmar que a abertura de capital de uma empresa não é a solução para o processo sucessório das mesmas no momento atual
Como podemos verificar, a abertura de capital e o processo sucessório de uma empresa apresentam objetivos conflitantes no presente momento do mercado de capitais brasileiro. $\mathrm{O}$ objetivo primordial do processo sucessório está na necessidade de obtenção de liquidez para os investimentos realizados pelos controladores. Essa liquidez é o caminho para que os herdeiros possam viabilizar seus desejos individuais sem criar conflitos no desenvolvimento da empresa. A abertura de capital de uma empresa, por sua vez, não garante a liquidez almejada pelos sucessores devido às características presentes do mercado de capitais brasileiro de baixa negociabilidade e valores inferiores aos patrimoniais para as açōes ordinárias.

Para que a abertura de capital de uma empresa seja uma das soluçôes para o processo sucessório das empresas brasileiras, é necessário que se processe o desenvolvimento do mercado de capitais como um todo. Uma maior quantidade de recursos a serem investidos, um melhor
Para que a abertura de capital de uma empresa seja uma das soluçöes para • processo sucessório das empresas oles, e necessário que se processe capitais como um todo. relacionamento entre as empresas abertas e seus acionistas e um maior nível técnico por parte dos analistas de investimentos, bem como uma estrutura menos oligopolizada por parte das instituiçōes financeiras, gerarão um amadurecimento dos participantes desse mercado.

Esse desenvolvimento trará um realinhamento nos preços das ações em bolsa, elevando-os, no mínimo, ao valor patrimonial real, e uma maior liquidez para as ações ordinárias. Assim, os objetivos da abertura de capital de uma empresa e o seu processo sucessório terão seus conflitos minimizados. 